\title{
BENDING FATIGUE STRENGTH OF SMALL SIZE 2 MM MODULE GEARS
}

\author{
FRANCO CONCLI \& LORENZO FRACCAROLI \\ Libera Università di Bolzano/Bozen, Piazza Università, Italy
}

\begin{abstract}
Nowadays the use of gears has significantly increased due to new materials available and to the high variety of possible applications. The necessity to investigate the gears behavior in different conditions plays a pivotal role for the evolutionary process of this so widely used mechanical component. In addition, the miniaturization process that is still growing in most of the engineering fields brings the necessity to accurately analyze the material properties, and fatigue behavior of gears having reduced dimensions. In this framework, in this work an experimental analysis combined with theoretical calculation was used for describing the fatigue behavior of $2 \mathrm{~mm}$ module gears made of 39NiCrMo3. Single Tooth Bending Fatigue (STBF) tests were performed according on a tensile testing machine. Since the machine grippers were not suited for fatigue tests on gears, a dedicated test-tool was appositively manufactured to exploit the Wildhaber W5 property. Tests were performed at different loading levels following the stair-case approach. Test were performed with a $\Delta \mathrm{F}$ of $100 \mathrm{~N}$. The fatigue limit was computed using the statistic Dixon approach that allows a precise calculation of the fatigue limit also with a reduced number of experimental data. The results in terms of measured forces were converted into the corresponding stresses using the ISO 6336 approach. Thereafter, the results were compared with the one stated in the ISO standard for the same steel material.
\end{abstract}

Keywords: gears, STBF, 39NiCrMo3, fatigue.

\section{INTRODUCTION}

Nowadays, the use of miniaturized components is still growing in the mechanical sector. Hence, the use of $2 \mathrm{~mm}$ or less modules for the design of small gearboxes has significantly increased due to the various possible applications, like robotics, high power density transmission systems and all the applications related to the automotive sector. In this important field of mechanic, it was also demonstrated that the use of small sized gears can reduce pollution [1]. All these facts lead to the necessity to correct investigate the material behavior when used for manufacturing small gears. In particular, this work is aimed in highlighting the steps necessary to compute the material properties, namely the admissible root tooth bending stress $\sigma_{\text {Flim }}$, and to report the results for a $39 \mathrm{NiCrMo} 3$ steel. In literature several standards are available for the design of gears, such as the EU ISO 6336 [2], the German DIN 3990 [3] and the US ANSI/AGMA 2001-D04 [4]. However, such standards are based on data obtained on $5 \mathrm{~mm}$ module gears. Several works on gears having a normal module $m_{n} \geq 5$ [5]-[9] have highlighted the inaccuracy of the actual standards in predicting the fatigue strength. In particular it was shown that the size of the gear significantly affects the resistance of the solution. A research made by Steutzger [10], showed that for what concern the tooth root bending load-carrying capacity, the adoption of gears with normal module $m_{n}>5$ is unfavorable. This evidence was confirmed by other scholars [11]-[13]. The tooth root bending behavior of big sized gears (nitrided and carburized) was already investigated by different scholars [14]-[16].

The gears behavior is influenced by several factors like the heat treatment, the surface finishing, temperature and the effective geometry of the gear, just to highlight some of the most important ones. Recently, some works in which small sized gears were investigated have been published [17], however this it is not still enough for having reliable data for the 
design phase of gears that have a normal module $m_{n}<5$. The ISO 6336 method B provides an approach which relies on the comparison between the permissible stress $\sigma_{F P}$ and the effective stress acting on the tooth $\sigma_{F}$. According to the standard, the two stress components are calculated according to eqns (1) and (2).

$$
\begin{aligned}
& \sigma_{F 0}=\frac{F_{t}}{b \cdot m} \cdot Y_{F} \cdot Y_{S} \cdot Y_{\beta} \cdot Y_{B} \cdot Y_{D T}, \\
& \sigma_{F}=\sigma_{F 0} \cdot K_{A} \cdot K_{V} \cdot K_{F \beta} \cdot K_{F \alpha} .
\end{aligned}
$$

Considering the geometry specification and the application of the gear inspected $Y_{\beta}, Y_{D T}$ and $Y_{B}$ were set equal to 1 reducing the formulation at eqn (3)

$$
\sigma_{F}=\frac{F_{t}}{b \cdot m} \cdot Y_{F} \cdot Y_{S} \cdot K_{A} \cdot K_{V} \cdot K_{F \beta} \cdot K_{F \alpha}
$$

where the form factor $Y_{F}$ is defined as eqn (4) and the stress correction factor $Y_{S}$ as eqn (5).

$$
Y_{F}=\frac{\frac{6 h_{F e}}{m} \cdot \cos \alpha_{F e n}}{\left(\frac{s_{F n}}{m_{n}}\right)^{2} \cdot \cos \alpha_{n}} .
$$

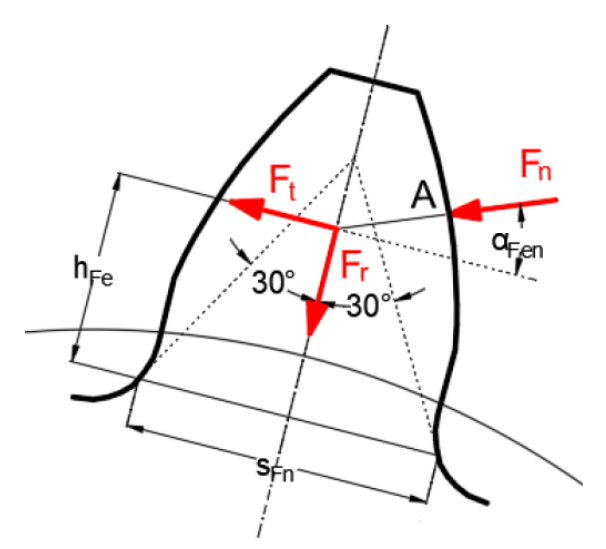

Figure 1: Representation of geometrical tooth parameters necessary for the computation of the $Y_{F}$ factor.

$$
Y_{S}=(1.2+0.13 \cdot L) \cdot q_{S}^{\frac{1}{1.21+\frac{2.3}{L}}}
$$

With $L$ defined as eqn (6) and the notch sensitivity $q_{s}$ computed thanks to eqn (7)

$$
\begin{aligned}
& L=\frac{s_{F n}}{h_{f e}}, \\
& q_{s}=\frac{s_{F n}}{2 \cdot \rho_{F}} .
\end{aligned}
$$


The application factor $K_{A}$ depends on the applications because it considers the external loading effects. $K_{V}$, also called, dynamic factor takes into account internal dynamics loads while the last two factors $K_{F \alpha}$ and $K_{F \beta}$ are used to manage transvers and uneven loads acting on tooth during contacts. These phenomena can be caused by the deflection of the component during operation ore by manufacturing errors.

As stated, form ISO 6336 method B, the allowable stress of the material defined as $\sigma_{F P}$ can be determined and compared with the one acting on tooth $\sigma_{F} . \sigma_{F P}$ is described by eqn (8)

$$
\sigma_{F P}=\sigma_{F l i m} \cdot Y_{S T} \cdot Y_{N T} \cdot Y_{\delta r e l T} \cdot Y_{R r e l T} \cdot Y_{X} .
$$

By comparing eqns (8) and (3) it is possible to compute $\sigma_{\text {Flim }}$ with eqn (9)

$$
\sigma_{F l i m}=\frac{F t}{b \cdot m} \cdot \frac{Y_{F} \cdot Y_{S}}{Y_{S T} \cdot Y_{N T} \cdot Y_{\delta r e l T} \cdot Y_{R r e l T} \cdot Y_{X}}
$$

$Y_{S T}$ and $Y_{N T}$ that are respectively the stress correction factor and life factor for the single tooth root stress. $Y_{\delta r e t T}$ considers the notch while $Y_{\text {Rrelt }}$ the surface of the component. The size factor $Y_{X}$ considers the dimension of the single tooth for the tooth root bending stress. It takes into account how the presence of weak points into the material, stress gradients, the presence of defect etc. [2] are influenced by the size of the gear. By consulting the normative ISO 6336 method $\mathrm{B}$, for gears that have a module $m<5$ the size factor $Y_{X}$ is always equal to 1 . Since this fact can lead to an oversizing of the gear, Dobler et al. [18] proposed an alternative method for computing the size factor $Y_{X}$ for gears having a fine module. The size factor proposed by Dobler is reported in eqn (10)

$$
Y_{X D o b l}=1-0.45 \cdot \log \left(\frac{m_{n}}{5}\right) \pm 0.075
$$

Moreover, since in this work were performed following the STBF tests procedure and not with meshing gears, it was necessary to introduce an additional correction factor [19], [20] to take into account the slightly different loading condition. Since the objective of this work was to compute the STBF fatigue limit of the material and to evaluate its behavior under cycling loads, an inverse application of the ISO 6336 standard, including the model by Dobler et al. [18] for what concern the size factor, is applied to convert the experimental data into stresses.

\section{MATERIAL AND METHODS}

In order to calculate the tooth root limit value $\sigma_{\text {Flim }}$, STBF test were performed on a fine module $\left(m_{n}=2\right)$ gear made of $39 \mathrm{NiCrMo}$. In Table 1 are resumed the relevant properties of the gear analyzed. For the computation of $Y_{F}, Y_{S}$ and the different correction factors, dimension needed were directly extracted from the $2 \mathrm{D}$ cad drawings.

Tests were performed on a SETPlab UD 04 pulsatory machine capable to apply a maximum load of $5 \mathrm{KN}$. A dedicated machine tool was appositively manufactured for correctly applying the load on the inspected tooth pair. A schematic representation of the setup used is shown in Fig. 2. As it is possible to see the gear position is constrained, during the mounting phase, by a central pin. Before starting the test, a load was applied to the gear and the pin removed. Exploiting friction, it is possible to avoid slipping of the gears before and during the test. A stress ratio $R=0.1$ was kept during the test. According to literature [15], [21], this value is enough for avoiding unwanted movement. 
Table 1: Tested gear geometry specification.

\begin{tabular}{|l|c|}
\hline Nominal module $\left(m_{n}\right)$ & $2.00(\mathrm{~mm})$ \\
\hline N. of teeth $(z)$ & $26(-)$ \\
\hline Normal pressure angle $\left(\alpha_{n}\right)$ & $20\left(^{\circ}\right)$ \\
\hline Face width $(b)$ & $20.00(\mathrm{~mm})$ \\
\hline Profile shift coefficient $(x)$ & $0.30(-)$ \\
\hline Dedendum coefficient $\left(h_{F p}^{*}\right)$ & $1.25(-)$ \\
\hline Addendum coefficient $\left(h_{a p}^{*}\right)$ & $1.00(-)$ \\
\hline Root radius factor $\left(\rho_{F p}^{*}\right)$ & $0.38(-)$ \\
\hline Wildhaber $(w)$ & $5(-)$ \\
\hline Formal correction factor $\left(Y_{F}\right)$ & 2.02 \\
\hline Stress correction factor $\left(Y_{S}\right)$ & 1.90 \\
\hline
\end{tabular}

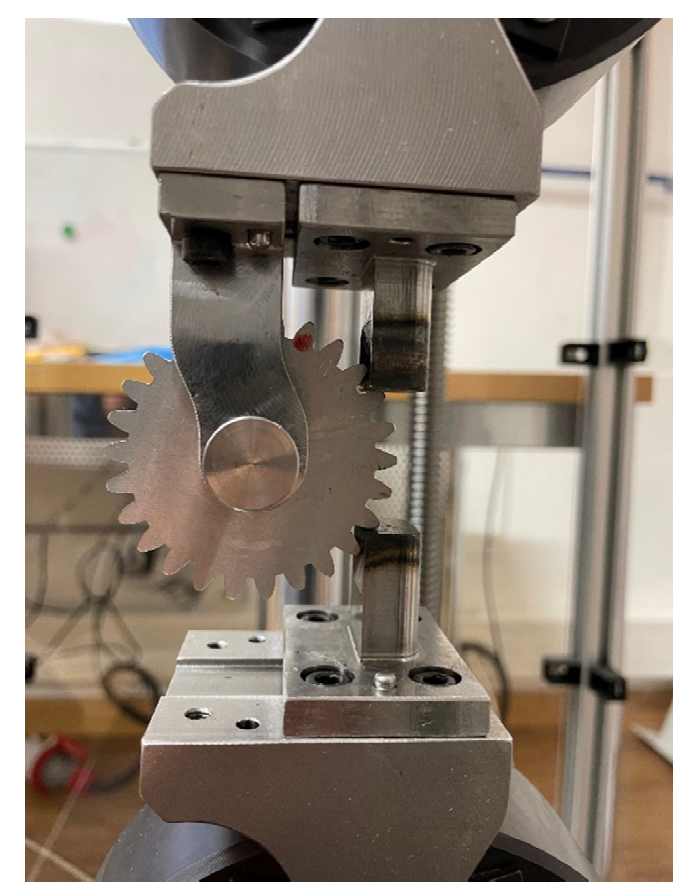

Figure 2: Machine set up used for tests with the gear mounted in the middle.

With this specific geometry the Wildhaber $W 5$ was used. In other words, $W 5$ means that there are five teeth within the anvils. The Wildhaber distance is strictly connected to the geometry of the gear since it must be chosen in order to apply a load which is normal to the gear tooth surfaces. To evaluate the STBF limit the short staircase approach was used. Specifically, several tests were performed at different load levels. This method predicts to define a constant force increment $\Delta F$. The choice of this value influences the accuracy of the final results. A low $\Delta F$ value will increase the accuracy but also the number of tests needed for reaching failure. The method works as follows. If a certain test reach fails or 
reach the run-out condition (withstand $5 \mathrm{M}$ cycles) with a force $F_{i}$, the next test is performed at a force level defined by $F_{i+1}=F_{i} \pm \Delta F$ respectively. The fatigue limit at a $50 \%$ probability is computed considering the first relevant force $F_{1}$ observed that induces a failure (eqn (11)). $k$ is a statistic factor that depends on the Run-out/Failure (RO/F) test sequence.

$$
F_{F P S T B 50 \%}=F_{1}+k \cdot \Delta F
$$

\section{RESULTS}

In Table 2 are resumed STBF tests performed on specimen gears. All dimensions necessary for the computation of correction factors were extrapolated directly from $2 \mathrm{D}$ drawings of the gear.

Table 2: Staircase results on the $2 \mathrm{~mm}$ module gear.

\begin{tabular}{|c|c|c|c|c|}
\hline Test & $F n_{\min }[N]$ & $F n_{\max }[N]$ & $N[-]$ & Status \\
\hline 1 & -395 & $-3,950$ & $3,330,753$ & $\mathrm{~F}$ \\
\hline 2 & -385 & $-3,850$ & $5 e 10^{6}$ & $\mathrm{RO}$ \\
\hline 3 & -395 & $-3,950$ & $5 e 10^{6}$ & $\mathrm{RO}$ \\
\hline 4 & -405 & $-4,050$ & 417,250 & $\mathrm{~F}$ \\
\hline 5 & -395 & $-3,950$ & $5 e 10^{6}$ & $\mathrm{RO}$ \\
\hline 6 & -405 & $-4,050$ & $5 e 10^{6}$ & $\mathrm{RO}$ \\
\hline
\end{tabular}

Firstly, the force must by multiplied by the angle $\alpha_{F e n}$ (see Fig. 1) to compute the acting tangential force $F_{t}$. According to the staircase approach for a RO/F sequence (F-RO-RO-FRO-RO), the value of the constant results $k=-0.296$. The application of eqn (9) leads to the calculation of the force associated to the $50 \%$ probability of failure, $F_{F P_{S T B F_{50}}}=$ 3,071.6 N. In Fig. 3 the result of the short staircase is plotted.

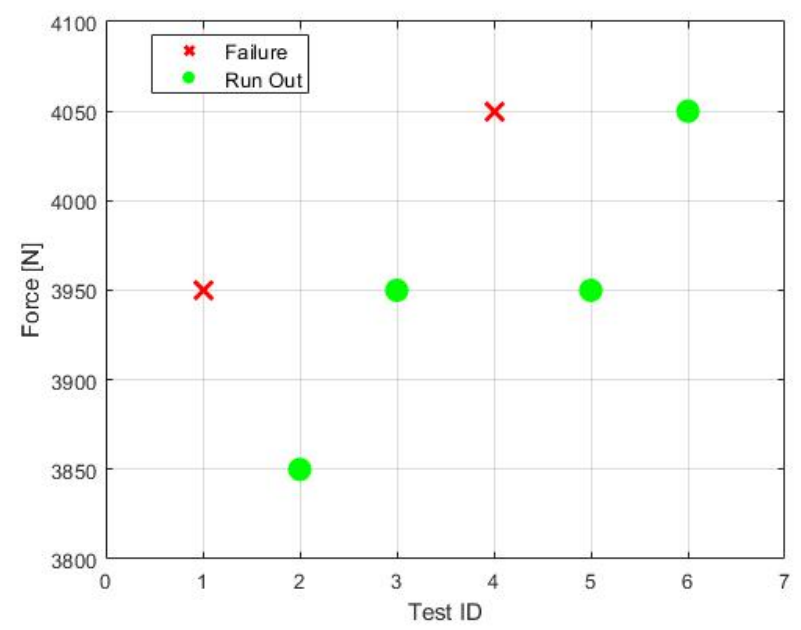

Figure 3: Staircase of the tested specimens. 
According to the equations mentioned in the first section $\sigma_{F 2 m m}=658.47 \mathrm{MPa}$. This value must now be multiplied by 0.9 to consider the fact that tests were performed on a pulsatory machine and not on meshing gears [19], [20]. With the introduction of this parameter now the effective bending stress present reduces to $\sigma_{F 2 m m}=592.63 \mathrm{MPa}$. The correction factors necessary for the computation of $\sigma_{F P}$ were chosen as follow. For our tested gear $Y_{S T}$ is equal to 2 and $Y_{N T}$ was equal to 1 . $Y_{\text {RrelT }}$ depends on the gear surface roughness $R_{z}$. The measured roughness $R_{a}$ of the specimen was $6.3 \mu \mathrm{m}$, it is possible to translate the value of $R_{a}$ into $R_{z}$ using the DIN 4778 [22]. According to ISO 6336 the associated value to of the relative surface factor with $R_{z}=38.3 \mu \mathrm{m}$ is $Y_{\text {RrelT }}=0.9458$. Considering the geometry, the notch sensitivity factor computed thanks to eqn (12) was $Y_{\delta \text { relT }}=0.9475$, were $X^{*}$ is the relative stress gradient and $\rho^{\prime}$ the slip-layer thickness. (for the computation of these value please refer to [2] and [23].)

$$
Y_{\text {SrelT }}=\frac{1+\sqrt{\rho^{\prime} \cdot X^{*}}}{1+\sqrt{\rho^{\prime} \cdot X_{T}^{*}}} .
$$

The size factor $Y_{X}$ was calculated with the new formulation proposed by Dobler et al. [18] (eqn (8)) with a resulting value of $Y_{X}=1.18$ instead of the unit value proposed by the standard. Finally, the admissible root tooth bending stress computed with eqn (9) was found out at $\sigma_{\text {Flim }}=280.44$. Moreover, thanks to the STBF tests performed it was also possible to reconstruct the characteristic S-N curve for the component. Data are plotted in Fig. 4.

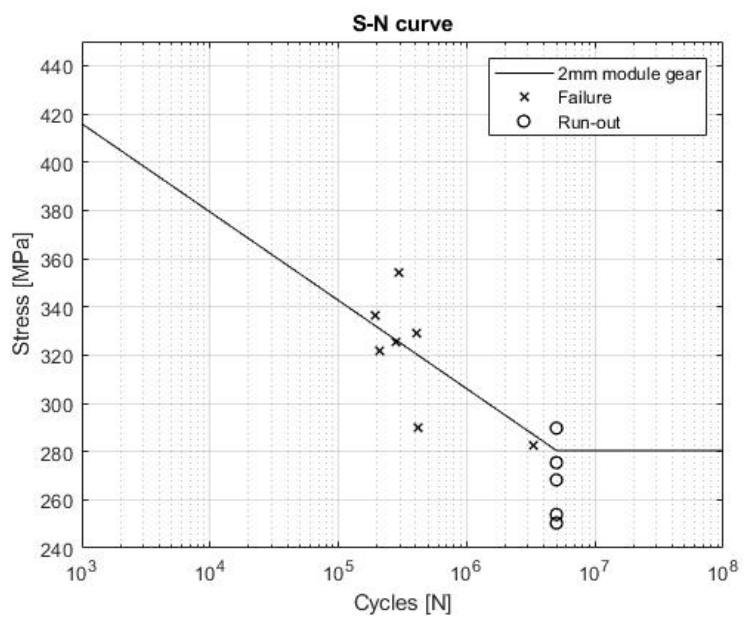

Figure 4: S-N curve of the component.

\section{CONCLUSION}

According to literature the admissible stress for the material $39 \mathrm{NiCrMo} 3$ is $\sigma_{\text {Flim }}=$ 280.92 $\mathrm{MPa}$. The experimental evidence $280.44 \mathrm{MPa}$ confirms the increased load carrying capacity of small gears observed by Dobler et al. [18] In other words, gears made by the same $39 \mathrm{NiCrMo} 3$ steel show a $18 \%$ increased load carrying capacity with respect to the performances of the same materials when used on standard $5 \mathrm{~mm}$ module gears. The experimental tests performed in this framework, fully confirm the findings of Dobler et al. 
[18]. For completeness, it should be mentioned that other formulations for the size factor are available in literature [17].

On the other hand, if standards were strictly followed, and an unitary value for the size factor is used, the present tests will lead to a $\sigma_{F l i m}$ equal to $330.65 \mathrm{MPa}$ which results about $17.7 \%$ higher than the one expected for this material. This fact highlights that there is the necessity to increase efforts to study also small gears that are and will become even more in the future, fundamental components for the mechanical industry.

\section{REFERENCES}

[1] Punov, P., Evtimov, T., Chiriac, R., Clenci, A., Danel, Q. \& Descombes, G., Progress in high performances, low emissions, and exergy recovery in internal combustion engines. Green Energy Technol., 1, pp. 995-1016, 2018.

[2] International Organization for Standardization, ISO 6336-3. ISO Stand., 3, ISO/DTS 6336-22, 2018.

[3] German Institute for Standardisation, DIN calculation of load capacity of cylindrical Gears-Introduction and general influence factors. 1987.

[4] American Gear Manufactures Association, ANSI/AGMA 2001-D04 fundamental rating factors and calculation methods for involute spur and helical gear teeth. 4, p. 66, 2004.

[5] Gorla, C., Rosa, F., Conrado, E. \& Concli, F., Bending fatigue strength of case carburized and nitrided gear steels for aeronautical applications. Int. J. Appl. Eng. Res., 12(21), 2017.

[6] Gorla, C., Conrado, E., Rosa, F. \& Concli, F., Contact and bending fatigue behaviour of austempered ductile iron gears. Proc. Inst. Mech. Eng. Part C: J. Mech. Eng. Sci., 232(6), 2018. DOI: 10.1177/0954406217695846.

[7] Rao, S.B. \& McPherson, D.R., Experimental characterization of bending fatigue strength in gear teeth. Gear Technol., 20(1), pp. 25-32, 2003.

[8] Gorla, C., Rosa, F., Concli, F. \& Albertini, H., Bending fatigue strength of innovative gear materials for wind turbines gearboxes: Effect of surface coatings. Proceedings ASME International Mechanical Engineering Congress and Exposition (IMECE), 7(Pt. A-D), 2012. DOI: 10.1115/IMECE2012-86513.

[9] Concli, F., Austempered ductile iron (ADI) for gears: Contact and bending fatigue behavior. Procedia Struct. Integr., 8, pp. 14-23, 2018.

DOI: 10.1016/j.prostr.2017.12.003.

[10] Steutzger, M., Großeneinfluss auf die Zahnfussfestigkeit, Frankfurt, Germany, 1997.

[11] Hertter, T., Rechnerischer Festigkeitsnachweis der Ermüdungstragfähigkeit vergüteter und einsatzgehärteter Stirnräder, Technische Universitaet Muenchen: München, Germany, 2003.

[12] Hoehn, B.-R., Oster, P. \& Braykoff, C., Size and material influence on the tooth root, pitting, scuffing and wear load carrying capacity of fine module gears.

[13] Hoehn, B.-R., Oster, P. \& Braykoff, C., Calcolo della capacità di carico degli ingranaggi con modulo piccolo. Organi di Trasm., 42, pp. 104-112, 2011.

[14] Conrado, E., Gorla, C., Davoli, P. \& Boniardi, M., A comparison of bending fatigue strength of carburized and nitrided gears for industrial applications. Eng. Fail. Anal., 78, pp. 41-54, 2017. DOI: 10.1016/j.engfailanal.2017.03.006.

[15] Gorla, C., Rosa, F., Conrado, E. \& Albertini, H., Bending and contact fatigue strength of innovative steels for large gears. Proc. Inst. Mech. Eng. Part C: J. Mech. Eng. Sci., 228(14), pp. 2469-2482, 2014. DOI: 10.1177/0954406213519614. 
[16] Bonaiti, L., Concli, F., Gorla, C. \& Rosa, F., Bending fatigue behaviour of 17-4 PH gears produced via selective laser melting. Procedia Struct. Integr., 24, pp. 764-774, 2019. DOI: $10.1016 /$ j.prostr.2020.02.068.

[17] Concli, F., Tooth root bending strength of gears: Dimensional effect for small gears having a module below $5 \mathrm{~mm}$. Appl. Sci., 2021.

[18] Dobler, A., Hergesell, M., Tobie, T. \& Stahl, K., Increased tooth bending strength and pitting load capacity of fine-module gears. Gear Technol., 33(7), pp. 48-53, 2016.

[19] Rettig, H., Ermittlung von zahnfußfestigkeitskennwerten auf verspannungsprüfständen und pulsatoren-vergleich der prüfverfahren und der gewonnenen kennwerte. Antriebstechnik, 26, pp. 51-55, 1987.

[20] Stahl, K., Lebensdauer statistik: Abschlussbericht, forschungsvorhaben nr. Tech. Rep., (304), p. 580, 1999.

[21] Gasparini, G., Mariani, U., Gorla, C., Filippini, M. \& Rosa, F., Bending fatigue tests of helicopter case carburized gears: Influence of material, design and manufacturing parameters. Am. Gear Manuf. Assoc. - Am. Gear Manuf. Assoc. Fall Tech. Meet, 2008(Dec.), pp. 131-142, 2008.

[22] G. I. for Standardisation, DIN 4778, Berlin, Germany, 1990.

[23] International Organization for Standardization, ISO 6336-5. ISO Stand., p. 50, 2003. 